\title{
NUTRITION AND FOOD LITERACY - CONCEPT, MEASUREMENT METHODS, DETERMINANTS, AND MEANING
}

\author{
Urszula Zwierczyk ${ }^{A, B, C, D, E, F}$, Mariusz Duplaga $A, B, C, D, E, F$
}

Department of Health Promotion and e-Health, Institute of Public Health, Faculty of Health Sciences, Jagiellonian University Medical College, Cracow, Poland, Poland

Authors' contribution:

A. Study design/planning • B. Data collection/entry $\bullet$ C. Data analysis/statistics $\bullet$ D. Data interpretation • E. Preparation of manuscript $\bullet$ F. Literature analysis/search $\bullet$ G. Funds collection

\author{
Address for correspondence: \\ Urszula Zwierczyk \\ Department of Health Promotion \\ and e-Health, Institute of Public Health, \\ Faculty of Health Sciences \\ Jagiellonian University Medical College \\ Cracow, Poland \\ e-mail: urszula.zwierczyk@uj.edu.pl \\ SUBMITTED: 15.10 .2021 \\ ACCEPTED: 10.11 .2021 \\ DOl: https://doi.org/10.5114/ppiel.2021.113788
}

\begin{abstract}
The notion of food or nutrition literacy refers to a person's ability to acquire, understand, and process food and nutrition-related information to make appropriate nutritional decisions. The aim of this study is to present the concepts of nutrition and food literacy, to indicate the methods of their measurement and the factors determining their level, and to determine their importance. The study is based on a selective review of the literature. Food and nutrition literacy is defined as a distinct form of health literacy. The difference between food and nutrition literacy is not clearly defined. Both nutrition and food literacy can be related to the categories of health literacy proposed by Nutbeam, including functional, interactive, and critical categories. However, food literacy appears to be more complex and, as stated by many authors, it corresponds with most of Nutbeam's categories. Nutrition literacy in the literature is generally described as the category of functional literacy. The level of nutrition and food literacy depends on many factors, such as age, gender, and level of education. Several instruments are available to determine the level of food and nutrition literacy. The most popular tools are the Nutrition Literacy Scale (NLS), Nutrition Literacy Assessment Instrument (NLit), Newest Vital Sign (NVS), Electronic Nutrition Literacy Tool (e-NutLit), and Short Food Literacy Questionnaire (SFLQ). Adequate levels of food and nutrition literacy are associated with beneficial dietary choices, which may be important in the prevention of chronic non-communicable diseases. Education and health communication interventions are crucial to improve food and nutrition literacy.
\end{abstract}

Key words: nutrition education, health literacy, nutrition literacy, food literacy.

\section{HEALTH LITERACY}

According to the World Health Organization (WHO), health literacy is defined as "the ability to gain access to, understand, and use information in ways that promote and maintain good health" [1]. Sørensen et al., in a systematic review of the literature on the existing definitions and models of health literacy, defined the concept as "the knowledge, motivation, and competences to access, understand, appraise, and apply health information in order to make judgments and take decisions in everyday life concerning health care, disease prevention, and health promotion to maintain or improve quality of life throughout the course of life" [2]. In simple terms, health literacy can be interpreted as the ability to understand and use information about health and illness [3]. It is worth noting that access to different types of health information, and the way knowledge is processed, is different for people of different ages [4]. But regard- less of the life situation, health literacy translates into the health status of a person. A high level of health literacy promotes adequate health decisions and individual well-being. From a society's perspective, higher health literacy contributes to more effective health policies, reduced health inequalities, and even reduced spending on health services [5]. It is worth noting that in order to achieve the desired level of health literacy, the focus should be on acting holistically. Every attribute of health literacy should be developed. From increasing the level of knowledge, through developing the skills to use it in practice, to the ability to critically evaluate health facts. The multidimensional development of health literacy enables health-promoting decision-making [4]. Health literacy involves several different aspects of individual behaviour and interaction with the health care system. Therefore, interventions to improve them should include an interdisciplinary approach that includes 
health promotion specialists, health education, psychologists, nutritionists, and medical professionals [6]. Furthermore, factors influencing health literacy, such as age and education level, should be taken into account when selecting health intervention methods to increase the effectiveness of the programmes [4].

\section{FOOD OR NUTRITION LITERACY?}

There is no doubt that one of the many determinants of human well-being is a healthy diet. Adequate knowledge, optimal dietary behaviour, and maintenance of normal body weight are now recognised as the key factors in health promotion that can prevent chronic non-communicable diseases [7]. Hence, attempts to introduce a concept referring to knowledge and skills related to nutrition are evident. In Englishlanguage publications, several terms are used to refer to nutrition and food-related literacy. These include terms such as 'nutrition literacy' [8], 'nutritional literacy' [9], and 'food literacy' [10]. To date, there is no term referring to these types of skills in the Polish language $^{1}$. To describe the effects of nutrition education, most often descriptive or complex formulations are used, e.g. 'knowledge of nutrition' [11], 'nutritional behaviour' [12], or 'nutritional choices' [13]. Sometimes we can also find the expression 'nutrition skills' [14].

The available definitions of nutrition literacy indicate that it is strongly linked to basic literacy and numeracy skills, which are necessary for understanding and using nutrition information [8]. Much of the definition of nutrition literacy has been coined by analogy with the definition of health literacy. For example, the definition given by Silk et al. states that nutritional literacy is the ability to acquire and understand information about food and nutrition in order to make appropriate nutritional decisions [15]. Guttersrud et al. proposed broadening the definition of nutrition literacy to include the ability to put knowledge into practice and to communicate with the community of nutrition professionals [16]. This definition indicates not only the individual but also the social and global context of nutrition literacy. Furthermore, these authors added to the definition of nutrition literacy the ability to evaluate the quality of nutrition information [17]. The multidimensional definition of nutritional literacy allows it to be seen from the point of view of the 3 categories included in the concept of health literacy proposed by Nutbeam, comprising functional, interactive, and critical literacy [4]. It is worth stressing that the definition by Guttersrud et al. is one of the few that describes nutritional literacy so broadly [16]. Unquestionably, nutrition literacy is more often defined from a functional perspective.

\footnotetext{
The Polish translation of the English terms quoted earlier leads to two terms: kompetencje żywieniowe in the case of the English terms 'nutrition literacy' and 'nutritional literacy' and kompetencje żywnościowe in the case of the English term 'food literacy'.
}

The concept of food literacy is broader than nutrition literacy. According to Fordyce-Voorham, food literacy means not only skills related to acquiring and processing information about food, nutrition, and its application in everyday life, but also the ability to prepare healthy meals and understand the impact of food on health, environment, and economy [17]. Sumner defines food literacy as the ability to 'read the world' in the context of nutrition [18]. This definition emphasises understanding the entire food production chain - where food is produced, how it is produced, who gains from buying it and who loses, who has access to it and who does not, and how it is disposed of. This comprehensive definition also includes the cultural, environmental, social, and economic importance of food and its implications with national policy. As Krause et al. point out, definitions of food literacy less often include references to health literacy as is the case with nutrition literacy [8].

\section{CATEGORIES OF FOOD LITERACY}

Following Nutbeam's proposal to distinguish 3 types of health literacy [4], 3 categories of food literacy can also be distinguished [4]. Functional food literacy refers to the understanding and use of information about food and nutrition [8]. This group of competences includes basic cooking skills, planning a shopping budget, and developing a balanced menu. Interactive food literacy focuses on the ability to communicate and exchange nutrition information with family or friends [8]. The category of critical food literacy is, according to Krause et al., the ability to evaluate food and nutrition information and consider it reliable or not [8]. To critical food literacy, the authors add the ability to assess the long-term impact of eating habits on an individual's health [8]. Other authors add further elements to the food literacy categories. Perry et al. add to functional food literacy the ability to read food labels and, based on this, to choose products with higher nutritional value and to give up processed products with low nutritional value declared on the label [19]. Interactive and critical food literacy includes nutrition with cultural, religious, or social aspects. By developing food literacy in these categories, nutritional decisions are also motivated by the environmental impact of food [19]. The Sustain Ontario organization has added to functional food literacy the knowledge of the origin of food and its chain from production to sale [20]. According to Colatruglio and Slater, interactive food literacy includes the ability to make decisions and set goals and dietary practices to achieve health and well-being [21]. Critical competencies are particularly important in situations of exposure to marketing influences. Critical food literacy allows one to evaluate the veracity of opinions made by other people, family, friends, or food and nutrition professionals [21] (Fig. 1). 


\section{DETERMINANTS OF NUTRITION AND FOOD LITERACY}

There is no clear description of the determinants of nutrition and food literacy in the literature. Moreover, authors of specific publications refer to both nutrition and food literacy. According to authors investigating the level of nutrition and food literacy, social, demographic, and economic factors can influence the level of nutrition and food literacy [22-24]. Franklin et al. demonstrated that nutrition literacy was related to body mass index (BMI). Theirs degree also depended on the level of health literacy [23]. As regards other factors related to the level of nutrition literacy, they confirmed that the presence of diseases among family members and being overweight or obese translated into corresponding levels of nutrition literacy [23]. Cassar et al. showed that age, gender, low socioeconomic status, and poor literacy and numeracy influenced levels of nutrition literacy [22]. On the other hand, Ringland et al. demonstrated that people with a university degree and those involved in daily shopping had higher levels of nutrition literacy [25]. Krause et al. added to the determinants of food literacy levels the degree of interest in food topics and the positioning of food in the individual hierarchy of needs [24].

\section{TOOLS FOR ASSESSING NUTRITION AND FOOD LITERACY}

Yuen et al. described 13 tools for assessing nutrition and food literacy in their systematic review [7]. None of them has been Polonized to date. Among them we can mention the following: the Nutrition Literacy Scale [26], Nutrition Literacy Assessment Instrument [27], Newest Vital Sign [28], Electronic-Nutrition Literacy Tool [25], and Short Food Literacy Questionnaire [24]. The Short Food Literacy Questionnaire was adapted to the Polish language by the authors of this article and was used to carry out the study; however, the authors do not have the results yet. Selected tools have been characterised below, based on their popularity.

The Nutrition Literacy Scale (NLS) was developed by Diamond in 2007. The NLS is a tool modelled on the Short Test of Functional Health Literacy in Adults (S-TOFHLA) [29]. This questionnaire was developed to assess nutrition literacy. This scale contains 28 questions on the effects of individual diet on cardiovascular health, saturated fatty acid intake, and meal portion sizes. Also, the questions include the content on organic food, dietary fibre, calcium, and sugar in food. The questions are ordered from the easiest to the most difficult. The NLS scale can be used to assess adults' ability to understand nutrition information [26].

A tool called the Nutrition Literacy Assessment Instrument (NLit) developed by Gibbs et al. [27] is also used to measure nutrition literacy. The NLit scale

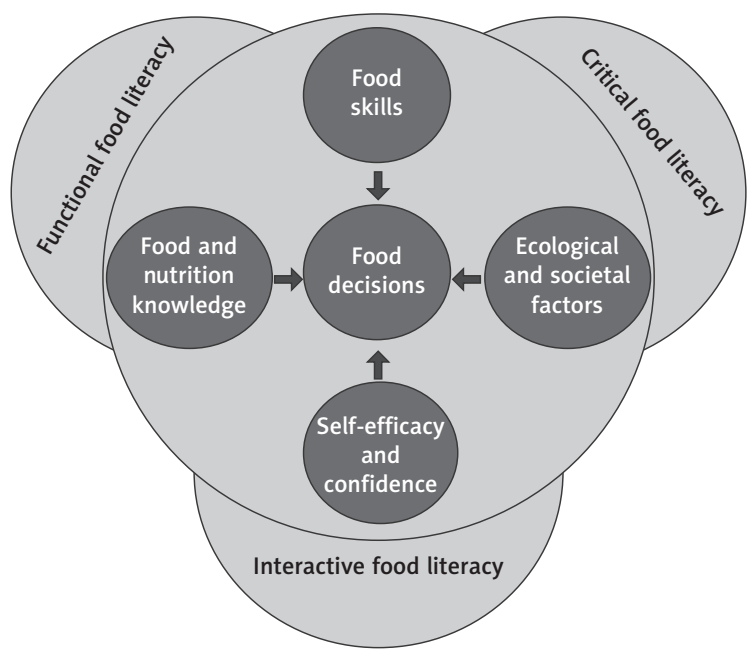

Figure 1. Categories of food literacy

consists of 6 subscales: nutrition and health, energy sources in food, food labels and counting skills, food and household quantity, food groups, and consumer skills. The NLit scale is available in 2 versions: a longer one with 64 questions and a shorter with 42 questions. The tool extensively examines nutrition literacy and is not limited to label reading skills, but also tests the ability to identify macronutrients in food. The questionnaire includes closed questions, sentences to be completed from which one or more words have been removed, and photographs to which specific questions refer. The Gibbs et al. tool is specifically for adults [27].

The Newest Vital Sign (NVS) test is a tool that is used to assess health literacy [28], but because it is based on understanding the information provided on a food label, it can also be used to measure nutrition literacy [30]. The NVS consists of 6 questions on the nutritional table on an ice cream package. According to the authors, the questionnaire can be completed in as little as 3 minutes, so it can find its application in studies among patients in clinics or hospitals to quickly assess the level of health and nutrition literacy [31].

Ringland et al. developed an electronic questionnaire to assess nutrition literacy, which they called the Electronic-Nutrition Literacy Tool (e-NutLit) [25]. The tool contains 24 questions that are divided into 2 sections. The first section includes 12 questions on demographics. Another 12 questions are the second section, on food label reading skills. The demographic characteristics include the usual questions such as age and gender, but also questions about the living conditions of the respondents. In the section related to label reading skills, there are questions about the respondent's participation in shopping, frequency of reading food labels, and the need to make changes in daily diet due to health conditions [25]. 
The Short Food Literacy Questionnaire (SFLQ) was developed by Krause et al. [24]. In the version available in German, the questionnaire contains 12 questions related to 3 categories of literacy described by Nutbeam. The questionnaire examines food literacy in functional terms, e.g. knowledge of the Swiss healthy food pyramid and salt intake recommendations; interactive, e.g. giving nutrition-related tips to relatives; and critical, e.g. the ability to evaluate food and nutrition information [24].

\section{THE SIGNIFICANCE OF NUTRITION AND FOOD LITERACY}

A high level of nutrition and food literacy determines beneficial dietary choices and may play an important role in the prevention of socially significant diseases [32]. Low levels of nutrition and food literacy may be related to purchasing unhealthy foods and succumbing to commercial marketing, which includes food advertising [33]. Gibbs et al. investigated the relationship between parents' nutrition literacy and their children's body mass index (BMI) and diet quality [34]. They used the Nutrition Literacy Assessment Instrument for Parents, developed from the NLit scale to assess nutrition literacy [34]. The quality of children's diet was measured using the Healthy Eating Index (HEI) [35]. The study showed that a $1 \%$ increase in the Nutrition Literacy Index leads to an increase of $0.51 \mathrm{HEl}$ points in children. Furthermore, it was shown that children of parents with high levels of nutritional literacy were more likely to have a normal BMI [35]. In contrast, Taylor et al. analysed the relationship between the level of nutrition literacy measured by the NLit scale and the dietary characteristics of people with chronic non-communicable diseases [36]. The study showed that individuals with higher nutrition literacy were more likely to follow a diet consistent with the Mediterranean diet, including more frequent consumption of vegetables and fruit as well as products containing unsaturated fatty acids, such as nuts, seeds, and vegetable oils. In contrast, the diets of respondents with lower dietary literacy more often corresponded to the Western style of eating and were characterised by a high consumption of products rich in saturated fatty acids, refined grains, and sweetened carbonated drinks [36]. Suliga et al. assessed the relationship between diet quality and nutrition knowledge among students from Poland, Germany, and Slovakia [37]. The authors used the Questionnaire of Dietary Habits and Nutrition Beliefs developed in Poland for individuals aged 15 to 65 years (KomPAN; Dietary Habits and Nutrition Beliefs Questionnaire) [38]. The highest level of nutritional knowledge was demonstrated in the group of the students from Poland followed by the students from Germany, while the students from Slovakia scored the lowest on food and nutrition knowledge. It appeared that the high level of nutritional knowledge found among Polish students did not translate into adequate quality of their diet. Although the German students showed a lower level of nutritional knowledge, their diet was characterised by a higher intake of legumes, vegetables, and fruit compared to the diet of the Polish students. In contrast, the diet of the Polish students was characterised by a high intake of red meat, fast food, and energy drinks. The authors emphasise that university authorities should strive to provide students on campuses with access to canteens that serve healthy and inexpensive meals. Furthermore, the authors' findings indicate a lack of developed nutrition literacy and all 3 categories of food literacy (functional, interactive, critical) that enable the use of food and nutrition knowledge in daily life [37].

\section{NUTRITION EDUCATION}

Nutrition education, as part of health promotion programmes, can make a significant contribution to improving nutrition and food literacy [39]. As Jarpe-Ratner et al. have shown, health education programmes through the development of elements of nutrition and food literacy provide an opportunity to increase the liking among children and adults for eating fruit and vegetables [39]. A rise in diet quality through nutrition education may contribute to lower body mass index (BMI) scores in the future and offers the chance to reduce the risk of lifestyle diseases [40]. Some programmes aimed at improving levels of nutrition and food literacy combine elements of increasing nutrition knowledge and an increase in practical nutrition-related skills, which are part of food literacy [41]. An example of such activities is the Australian Food Sensations for Adults programme [41]. This 4-week programme aimed to provide participants with knowledge about healthy nutrition, reading and interpreting food labels correctly, and choosing appropriate foods based on this, learning to budget, and practical cooking tips. On the basis of self-reported questionnaires, the effectiveness of the implemented activities was checked. Before the programme, more than $60 \%$ of the participants had a low level of food literacy. In contrast, after completing all modules, these individuals were able to raise their level of literacy. In addition, the authors showed a higher intake of fruit and vegetables compared to baseline and a reduction in consumption of sweetened carbonated drinks and fast food [41]. Another example of an effective intervention to increase food literacy based on nutrition education is the Italian Maestra Natura programme [42]. The main recipients of this programme are primary school children. Nutritional knowledge and practical tips for daily diet were taught to pupils during educational trails dur- 
ing the school year. A knowledge test at the beginning of the year showed poor knowledge regards fruit and vegetables. In contrast, after the programme was conducted and the students' knowledge was re-examined using the same test at the end of the school year, knowledge about fruit and vegetables increased by an average of $12 \%$ [42]. As a result, the students showed greater interest in their diet in terms of its importance for health, and the reluctance to eat vegetables decreased. Although the authors did not assess the level of food literacy in the study groups with validated food literacy survey tools, the findings indicate an increase in the level of knowledge and its practical application in the daily diet, which are elements of food literacy [42]. An evaluation of another health promotion programme involving nutrition education and cooking workshops among Chicago primary school children and their parents showed that this type of activity raises many elements of food literacy [38]. After a 10-week course, it was shown that the level of nutritional knowledge rose significantly, and participants improved their literacy in preparing healthy meals. What is more, the children who participated in the programme showed a higher consumption of vegetables and fruit than before [39]. Due to the presence of parents in part of the workshops, it was demonstrated that they were more willing to involve their children in the preparation of meals for the household and there were more frequent conversations at home about healthy food [39].

\section{CONCLUSIONS}

Nutrition and food literacy is now an important topic in health promotion. Including these concepts in countries' health policies can effectively contribute to improving health in society. In order to properly plan health promotion programmes in the field of nutrition, it is necessary to find out at which level nutrition and food literacy are developed in the population. There is no doubt that existing tools to assess the level of nutrition and food literacy can be applied in this regard. Health programmes that include nutrition education and its practical application on a daily basis seem to be a good combination, which leads to increased levels of nutrition and food literacy. A comprehensive approach to activities aimed at raising nutrition and food literacy provides a chance to improve the quality of the diet and reduces the risk of future lifestyles diseases.

\section{Disclosure}

The authors declare no conflict of interest.

\section{References}

1. World Health Organization. Health Promotion Glossary, Geneva 1998; 10.
2. Sørensen K, Van den Broucke S, Fullam J, et al. Health literacy and public health: A systematic review and integration of definitions and models. BMC Public Health 2012; 12: 80.

3. Niedorys-Karczmarczyk B, Chrzan-Rodak A, Bartoszek A, et al. Kompetencje zdrowotne (Health Literacy) - przegląd badań z wykorzystaniem Europejskiego Kwestionariusza Kompetencji Zdrowotnych (HLS-EU-Q47) w latach 20102018. Hygeia Public Health 2019; 54: 105-113.

4. Nutbeam D. Defining, measuring and improving health literacy. University of Southampton 2015.

5. Duong TV, Aringazina A, Baisunova G, et al. Measuring health literacy in Asia: Validation of the HLS-EU-Q47 survey tool in six Asian countries. J Epidemiol 2017; 27: 80-86.

6. Klinovszky A, Papp-Zipernovszky O, Buzás N. Building a house of skills - a study of functional health literacy and numeracy among patients with type 2 diabetes in Hungary. Int J Environ Res Public Health 2021; 18: 1-14.

7. Yuen EYN, Thomson M, Gardiner H. Measuring nutrition and food literacy in adults: a systematic review and appraisal of existing measurement tools. Health Lit Res Pract 2018; 2: e134-e160.

8. Krause C, Sommerhalder K, Beer-Borst S, et al. Just a subtle difference? Findings from a systematic review on definitions of nutrition literacy and food literacy. Health Promot Int 2016; 33: 378-389.

9. Ayer A, Ergin A. Status of nutritional literacy in adolescents in the semi-rural area in Turkey and related factors. Public Health Nutr 2021; 24: 3870-3878.

10. Fingland D, Thompson C, Vidgen HA. Measuring food literacy: Progressing the development of an international food literacy survey using a content validity study. Int J Environ Res Public Health 2021; 18: 1141.

11. Legg C, Puri A, Thomas N. Dietary restraint and self-reported meal sizes: Diary studies with differentially informed consent. Appetite 2000; 34: 235-243.

12. Seń M, Zacharczuk A, Lintowska A. Zachowania żywieniowe studentów wybranych uczelni wrocławskich a wiedza na temat skutków zdrowotnych nieprawidłowego żywienia. Pielęgniarstwo i Zdrowie Publiczne 2012; 2: 113-123.

13. Gacek M, Chrzanowska M. Wybory żywieniowe aktywnych zawodowo mężczyzn z populacji krakowskiej w zależności od wieku. Problemy Higieny i Epidemiologii 2007; 88: 327-331.

14. Wilson CK, Matthews JI, Seabrook JA, et al. Self-reported food skills of university students. Appetite 2017; 108: 270-276.

15. Silk KJ, Sherry J, Winn B, et al. Increasing nutrition literacy: testing the effectiveness of print, web site, and game modalities. J Nutr Educ Behav 2008; 40: 3-10.

16. Guttersrud O, Dalane JO, Pettersen S. Improving measurement in nutrition literacy research using Rasch modelling: Examining construct validity of stage-specific "critical nutrition literacy" scales. Public Health Nutr 2014; 17: 877-883.

17. Fordyce-Voorham S. Identification of essential food skills for skill-based healthful eating programs in secondary schools. J Nutr Educ Behav 2011; 43: 116-122.

18. Sumner J. Food literacy and adult education: learning to read the world by eating. The Canadian Journal for the Study of Adult Education 2013; 79-92.

19. Perry EA, Thomas H, Samra HR, et al. Identifying attributes of food literacy: A scoping review. Public Health Nutrition 2017; 20: 2406-2415.

20. Sustain Ontario. Backgrounder on Food Literacy, Food Security, and Local Food Procurement in Ontario's Schools. 2013.

21. Colatruglio S, Slater J. Challenges to acquiring and utilizing food literacy: Perceptions of young Canadian adults. Canadian Food Studies 2016; 3: 96-118. 
22. Cassar AM, Denyer GS, O'Connor HT, et al. A qualitative investigation to underpin the development of an electronic tool to assess nutrition literacy in Australian adults. Nutrients 2018; 10: 251

23. Franklin J, Holman C, Tam R, et al. Validation of the e-NutLit, an electronic tool to assess nutrition literacy. J Nutr Educ Behav 2020; 52: 607-614.

24. Krause CG, Beer-Borst S, Sommerhalder K, et al. A short food literacy questionnaire (SFLQ) for adults: Findings from a Swiss validation study. Appetite 2018; 120: 275-280.

25. Ringland E, Gifford JA, Denyer GS, et al. Evaluation of an electronic tool to assess food label literacy in adult Australians: A pilot study. Nutr Diet 2016; 73: 482-489.

26. Diamond JJ. Development of a reliable and construct valid measure of nutritional literacy in adults. Nutr J 2007; 6: 5.

27. Gibbs HD, Ellerbeck EF, Gajewski B, et al. The nutrition literacy assessment instrument is a valid and reliable measure of nutrition literacy in adults with chronic disease. J Nutr Educ Behav 2018; 50: 247-257.e1.

28. Weiss BD, Mays MZ, Martz W, et al. Quick assessment of literacy in primary care: The newest vital sign. Ann Fam Med 2005; 3: 514-522.

29. Baker DW, Williams MV, Parker RM, et al. Development of a brief test to measure functional health literacy. Patient Educ Couns 1999; 38: 33-42.

30. Rowlands G, Khazaezadeh N, Oteng-Ntim E, et al. Development and validation of a measure of health literacy in the UK: The newest vital sign. BMC Public Health 2013; 13: 116.

31. Rodrigues R, Andrade SM, González AD, et al. Cross-cultural adaptation and validation of the Newest Vital Sign (NVS) health literacy instrument in general population and highly educated samples of Brazilian adults. Public Health Nutr 2017; 20: 1907-1913.

32. West EG, Lindberg R, Ball K, et al. The role of a food literacy intervention in promoting food security and food literacy ozharvest's nest program. Nutrients 2020; 12: 2197.

33. Guiné Raquel PF, Duarte J, Ferrão AC, et al. The eating motivations scale (EATMOT): Development and validation by means of confirmatory factor analysis (CFA) and structural equation modelling (SEM). Zdravstveno Varstvo 2020; 60: 4-9.

34. Gibbs HD, Kennett AR, Kerling EH, et al. Assessing the nutrition literacy of parents and its relationship with child diet quality. J Nutr Educ Behav 2016; 48: 505-509.

35. Guenther PM, Casavale KO, Reedy J, et al. Update of the Healthy Eating Index: HEI-2010. J Acad Nutr Diet 2013; 113: 569-580.

36. Taylor MK, Sullivan DK, Ellerbeck EF, et al. Nutrition literacy predicts adherence to healthy/unhealthy diet patterns in adults with a nutrition-related chronic condition. Public Health Nutr 2019; 22: 2157-2169.

37. Suliga E, Cieśla E, Michel S, et al. Diet quality compared to the nutritional knowledge of polish, german, and slovakian university students - preliminary research. Int J Environ Res Public Health 2020; 17: 1-13.

38. Jeżewska-Zychowicz M, Wadolowska L, Galiński G, et al. Dietary Habits and Nutrition Beliefs Questionnaire and the manual for developing of nutritional data. Olsztyn 2017.

39. Jarpe-Ratner E, Folkens S, Sharma S, et al. An experiential cooking and nutrition education program increases cooking self-efficacy and vegetable consumption in children in grades 3-8. J Nutr Educ Behav 2016; 48: 697-705.e1.

40. Qian Y, Nayga RM, Thomsen MR, et al. The effect of the fresh fruit and vegetable program on childhood obesity. Appl Econ Perspect Policy 2016; 38: 260-275.
41. Begley A, Paynter E, Butcher L, et al. Identifying who improves or maintains their food literacy behaviours after completing an adult program. Int J Environ Res Public Health 2020; 17: 4462.

42. Scazzocchio B, Varì R, D'amore A, et al. Promoting health and food literacy through nutrition education at schools: The Italian experience with Maestranatura program. Nutrients 2021; 13: 1547. 